\title{
State of art regarding to quantify the consequences associated with building response to an earthquake shaking
}

\author{
Ali Majdi ${ }^{1,2, *}$, and Radu Sorin Văcăreanu ${ }^{1}$ \\ ${ }^{1}$ Technical University of Civil Engineering Bucharest, 122-124 Lacul Tei Bvd., Bucharest, Romania \\ ${ }^{2}$ Al-Mustaqbal University College, Babylon, Iraq
}

\begin{abstract}
Earthquake loss estimation (ELE) refers to the analysis and study of the possible effects of an earthquake in a region or population and quantifies the consequences of the earthquake. The objective of this study is to provide an insight into earthquake loss estimation for the most common approaches by seeking to survey the current methodologies for quantifying the earthquakes' negative effects. Naturally, peoples search about desirable approaches to estimate of earthquakes costs and losses which are not predetermined to subsist as usual. Other issues related to those approaches are endeavor to achieve the state of art to quantify the earthquakes consequences, the aspects of a building's response to earthquake. The aspects that will be characterized in this research are: 1) Input data like building information (Structure system, location, occupation, etc.), earthquake hazard; 2) Analysis methods; 3) Output data. ELE methods are categorized in different ways depending on one or more parameter. ELE approaches into two groups (1a shocked building stock in a specific city or settlement, 2-specific building or structure). The varying and common use have been observed when selecting the approaches of this research. The methods and tools that used in the exploration include QLARM, SELENA, ELER, HAZUS, SLAT and FEMA P-58.
\end{abstract}

\section{Introduction}

The increasing of worldwide earthquakes significantly led to increasing of the costs of damages in both social and economic aspects, where the economic and social losses are a sign of the buildings damage because vulnerable earthquake damage. And the damages differ depending on the building ability for resisting the ground motion and geographical differences for this ground.

In the new buildings, it should take in consideration the effect of earthquake, so it is important to design these buildings to withstand a certain degree of damage in case of shake especially in earthquake-prone areas. As well as, old buildings should be upgraded by using of the latest technologies and approaches to minimize the damages that caused by seismic activities. This performance is related to various factors such as the damages that can be occurred when a building collapse, and other damage consequences such as loss of life, both economic and social impacts.

In this report, various earthquake loss estimation methods and tools will be studied to evaluate earthquake losses either for building stock in a specific area or a specific building. The characteristics that will be investigated include structural, building information such as the purpose, site location, area of floor, storey height, construction year, the vulnerability of components and also earthquake hazard. In most of ELE methods and tools, the performance is a measure regarding to the probability of having losses, the required cost to repair the damaged building, the time will take for a specific process among others. So, the purpose of performance measures is to estimate the social and economic losses for an earthquake that included the number of causalities, economic losses incurred and downtime. In order to produce an effective earthquake loss estimation ELE, four components must be taken into account which are: Exposure, Vulnerability, Hazard and Damage Loss Conversion.

The exposure could be defined as the amount of human activity that existed in the seismic hazard zones as specified in the stock of infrastructure in that location. Where the vulnerability is refer to the sensitivity of building to different types of damage, and the hazard is the probability of a certain ground motion occurring at a location, which can be determined by PSHA (Probabilistic Seismic Hazard Assessment) or other methods, which can include different types of earthquake influences; and Damage Loss Conversion can be defined in economically point of view as the average damage ratio of replacement to repair cost or the social losses such as the number of injuries or deaths.

\section{Earthquake Damage and Loss Estimation}

Predicting the likely consequences of an earthquake to a nation, a city or an individual facility is generally

\footnotetext{
* Corresponding author: alimajdi67@gmail.com
} 
covered by the scientific field of seismic risk assessment, often referred to as "Earthquake loss estimation (ELE)".

Seismic risk assessment is a comparably young discipline, which basically began with the seminal works on earthquake hazard by Luis Esteva and Allin Cornell in the late 1960s. An elementary definition of this discipline was given by the EERI Committee on Seismic Risk in 1984, according to which "seismic risk is the probability that social and economic consequences of earthquakes will equal or exceed specified values at a site, at various sites or in an area during a specified exposure time".

Earthquake loss estimation studies establish a central component in the causal chain from the basic research disciplines involved to prevention and mitigation actions against the causes of the natural hazard earthquakes (see Figure). The main purpose of earthquake loss assessment studies is to generate reliable estimates of expected physical damage as well as the economic and social losses that are connected to the damages either in a direct or indirect way. Based on the identification of existing weaknesses, e.g. the disproportionate damage extent of a certain building typology, strengthening and retrofitting measures can be proposed. Thus, earthquake loss assessment studies can directly contribute to the prevention of future losses.

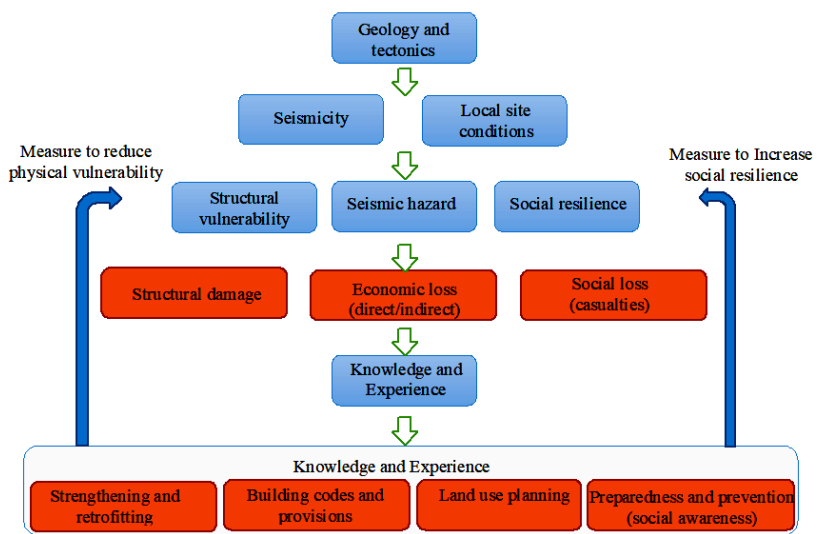

Fig. 1. Basic research chain to preventive actions of an earthquake loss estimation.

So, based on location and magnitude of a scenario earthquake and local geological data, ground motion demands are calculated in terms of response spectra and peak ground values (e.g., PGA and PGV). The estimation process follows three steps described below and is schematically:

- Specify attributes of the scenario earthquake including location, depth, magnitude, and fault rupture type, etc.

- Determine the ground motion levels for the bedrock using appropriate attenuation laws.

- Overlay high-resolution geologic data and modify the ground motion demands using site amplification factors based on local site-soil conditions.

Fragility curves are often used to estimate probability of reaching or exceeding various damage states, given estimates of seismic demands or structural responses. The fragility curve is often modelled as a lognormal function and is defined by a median value, $\bar{s}_{d}$ corresponding to the mean threshold of associated damage-state, and by a logarithmic standard deviation, $\beta$.
Thus, the conditional probability of being in, or exceeding, a particular damage state, di, given seismic demand, $\mathrm{s}_{\mathrm{d}}$, is defined by:

$$
P\left(D S \geq d_{i} \mid s_{d}\right)=\phi\left[\frac{1}{\beta} \ln \left(\frac{s_{d}}{\underline{s_{d}}}\right)\right]
$$

where (.) $\Phi$ is the standard normal distribution function.

As an example, if PGA is used in constructing a fragility curve, the fragility curves of a particular building can be constructed by following procedures stated below:

- Select earthquake ground motion model with hazard consistent PGA distribution;

- Define limiting states for discrete damage levels;

- Analyze the building response using incremental dynamic analysis IDA;

- Conduct risk analysis to obtain the probability of exceeding various limiting states.

In general, earthquake damage and loss studies are based either on the traditional empirical (or statistical) approach (i.e. macro-seismic intensities) or the more recent analytical (or theoretical) approach using physical ground-motion parameters such as spectral accelerations Sa or spectral displacements Sd. Especially in situations where statistical methods cannot be applied (e.g. due to lack of data or missing experience from previous earthquake damage), analytical tools may be used to supplement the loss estimation procedure, thus leading to a third, i.e. hybrid approach (Dolce et al., 1995; Kappos et al., 1998; Kappos et al., 2002). Hybrid approaches can, e.g., combine statistical (empirical) damage data with theoretical results from nonlinear structural analyses. In other words, it can be said that the different loss estimation approaches are differed principally in the way of representing earthquake ground motion and the treating of building vulnerability (Lang et al., 2012a). With respect to the latter, the 'damageability' according to (Lang et al. 2012a4) or the 'damagingness' according to (Coburn and Spence, 2002) as a different notation of a building's vulnerability which can be obtained by a various method (empirical, analytical, experimental, expert opinion or a combination of these methods).

\section{Methodology}

The challenge for the engineers and designers for selection a proper ELE methodology is very high. And the selection should be done by following of some steps, the first step that must have an overview of existing ELE literature which including understanding and choose of exposure technique such as remote sensing (which provide a time efficiency and data accuracy and used as an indication to estimate earthquake hazard accurately and rapidly; and it just takes a limited time in the right decision-making after the disaster within a short time) or other technique. Also, they should understand and select the vulnerability type such as empirical, analytical or hybrid; as well as select the hazard methods deterministic or probabilistic, and beside that identify the results from the methodology if estimate just economic 
or social losses or both of them. After this step of overview, the second step comes to evaluate the ELE methodology and tool, which include Acquisition of information, documentation and tools of all possible available set of data that related to test regions. And that data can be edited to be suitable for the location as well as this data set should be evaluated. The final step is to select the proper methodology that is eligible for exposure, vulnerability, earthquake hazard and losses.

However, the selected approaches in this report show that the process of estimating building-specific economic losses can become complicated due to the type and amount of required information and computations. The first group methods of ELE are QLARM, SELENA and ELER, which they calculate the economic and human losses for the general building stock and population of a specific region. The second group methods in this report are HAZUS, SLAT and FEMA P-58.

The essential method is used in this report to analyses these methods regarding to their functions of loss estimation. Where there is no exact case studies or computations to compare the methods, the comparison is performed through a literature review using published information such as official website, user manuals and guides that created by the developers and some other related references which examined and compared.

Depending on the evaluation of literature and comparisons, this research gives an overview on the characteristics, similarities and limitations for each method.

\section{Loss Estimation methods}

The trend of the number of damaging earthquakes is slightly increasing, due to exposure and better recording, but not significantly. Economic losses have been increasing in both the developed and non-developed world from earthquakes even when using an inflationadjusted, or construction cost adjusted trend. Due to the increases in populations the rate of exposure to earthquakes is increasing, and while better standards of construction are being practices in some countries, in many earthquake-prone countries buildings are being constructed without much regard to building codes. Earthquake loss estimation methods have been around since the 1970's, but with advances in technology, these methods are finding roles in many areas of earthquake planning. While early efforts concentrated only on planning scenarios for mitigation response (i.e., determining the level of resources after a major event, and where to deploy them), earthquake loss estimation is also now being increasingly applied to loss estimation after a major earthquake (this currently 'applies mostly to insurance estimates of loss after a significant event); evaluation of the effectiveness of mitigation measures and/or strategies (i.e., cost benefit analysis).

\subsection{QLARM}

The QLARM (Quake Loss Assessment for Response and Mitigation) is an open source tool developed by a Swiss- based International Center for Earth Simulation (ICES). QLARM tool is used by engineers and other professionals to estimate and allocate the level of building damages and the associated number of casualties that caused by earthquake. QLARM provides an earthquake loss alert in real time (within 30 minutes in medium) (ICES, 2013). It could also be used to estimate the expected losses in the future events. Where it uses the population database, 2013 data containing at approximately 2 million settlements (name, coordinates, and population). The data on buildings follows the information of the World Housing Encyclopedia (ICES, 2013). As well as QLARM uses earthquake source parameters from German Research Center (GFZ) and US Geological Survey (USGS).

The output of this tool comes in the form of a table that gives a list of parameters for every database settlement. Some of the parameters that are listed by the tool include the intensity, the average damage of every building, the general average damage, the number of injured individuals, and the fatality ranges. The tool gives two different types of maps; the first type of map is the expected intensity at every settlement and the expected average damage of each settlement (FEMA, 2003).

QLARM uses the data-set: building class, population and building stock, distribution of population within the building stock, as well as district divisions for 49 large cities (Philippe and Max, 2017). The estimation of the ground motion parameters (Intensity, PGA, and PVA) is obtained by collect basic information of the earthquake: magnitude, longitude, latitude, depth and time and source to site distance. After running the analysis, the fragility course will be obtained and the damage degree for each vulnerability class will be calculated, from that the results are estimated of injured and killed peoples and mapping of damage per settlement and critical facilities. The module of QLARM is shown in Figure 2.

The limits of QLARM that it used just for minimum magnitude (M) of 5.9 and can't be used for estimating the losses in a specific building. In these methods no, economic losses are estimated. Furthermore, the results will be less accuracy if the study region has a different types of building stocks.

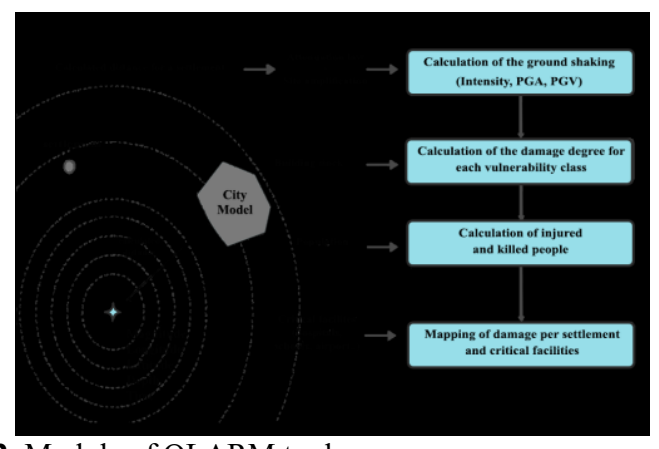

Fig. 2. Module of QLARM tool

\subsection{SELENA}

Seismic risk and loss analysis software (SELENA) is an open source software which developed by Norwegian 
research foundation NORASAR (Norwegian Seismic Array) and released in 2004 and using Logic Tree Approach. As well as it allows to the same approach as HAZUS loss estimation tool.

SELENA provides damage and loss estimates on the level of geographical units (NORSAR, 2010).

It uses large resources for purposes of eliminating both the vulnerability and capacity curves for buildings of varied building types and design category levels.

However, the usage of this tool is needing from the applicable to give various input files that contain the required input data like demographic data, building inventory data, and definition of seismic scenario in a simple ASCII layout. This tool was developed to deal with the challenge of software accessibility to carry out the tasks that related to earthquake loss estimation. The basic operation of this tool is generally based on principle of capacity-spectrum method (CSM) and follows the same approach as the loss estimation tool for the United States HAZUS-MH (FEMA, 2004). But SELENA works independently of any Geographic Information System, unlike HAZUS which linked with ArcGIS software.

SELENA needs many data which should be given to estimate the losses, these data are: Buildings inventory data, with their Vulnerability; exposure; earthquake hazard; shaking map (shows the allocations of earthquake shaking levels which have a certain likelihood of happening), demography and economic models. The types of analysis that used in SELENA which (are different in the way the seismic impact) deterministic analysis, probabilistic analysis and analysis with real time data. In general, spectral ordinals of seismic ground motion at different reference periods have to be provided for each geographical unit (i.e., census tract), in order to allow the construction of a design spectra following a selectable seismic code provision (NORSAR, 2010).

SELENA provides the results of damage, economic and human losses for the general building stock and population of a city or country on the level of minimum geographical units. It applies the Capacity Spectrum Method to calculate the physical damage for the building stock after eliminating the ground motion in each geographic unit.

The total economic losses associated with these damages and number of fatalities (injured people and casualties) will be obtained. In addition to that, the numbers of Shelters and Debris will be estimated.

The form of the results that obtain from SELENA will be in terms of cumulative probabilities that reach or transcend the damage limit states that given by HAZUS$\mathrm{MH}$, these are: None, Slight, Moderate, Extensive and complete damage (NORSAR, 2010).

SELENA is modified and adapted in MATLABTM, where the users need an additional knowledge to understand and use it professionally. Like the previous method, SELENA is estimate earthquake losses in district level and can't apply in a specific building.

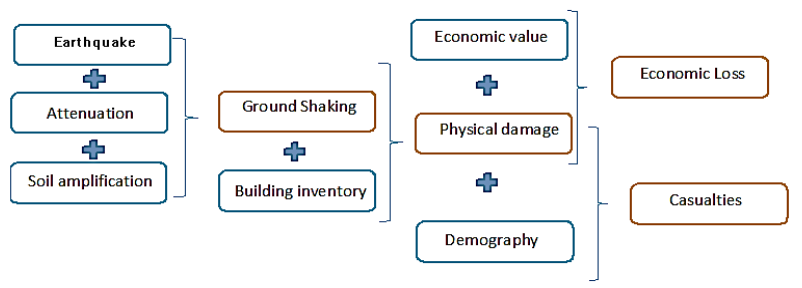

Fig. 3. Principle flowchart of a deterministic analysis using SELENA.

\subsection{ELER}

ELER (Earthquake Loss Estimation Routine) is a methodology which is developed by Bogazici University, Department of Earthquake Engineering in 2009 under the JRA-3 component of the EU FP-6 NERIES (NEtwork of Research Infrastructures for European Seismology) project for the rapid estimation of earthquake shaking and losses in the Euro-Mediterranean region (ELER, 2010). ELER consist of the detailed methodology and software that coded in MATLAB programming environment.

The brief description of the methodology procedure could be given by the following analysis steps, (ELER, 2010):

- The estimation of ground motion parameters (PGA, $\mathrm{PGV}, \mathrm{S}_{\mathrm{a}}$, and $\mathrm{S}_{\mathrm{d}}$ ) is achieved by prediction equations of specific ground motion and by shear wave velocity distributions or other site characteristics;

- Estimation of the building damage and human casualty at different levels of developments that associated with the availability of inventory of human built environment; - Estimation of direct economic losses that stemming from the damages of building;

- Estimation of damages for urban pipeline systems.

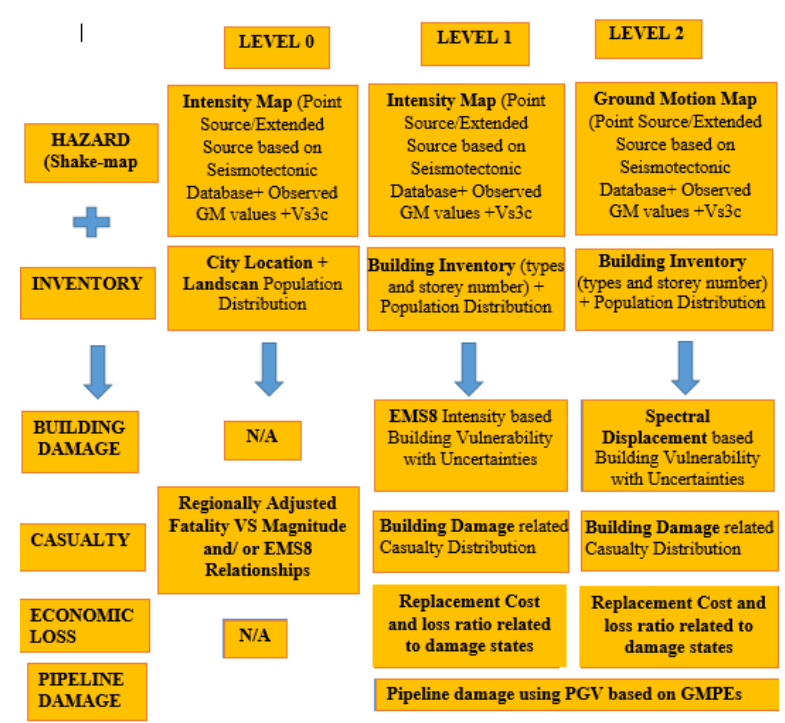

Fig. 4. The levels of analysis incorporated in the ELER software.

The software of ELER uses 4 modules: Hazard, Level 0, Level 1 and Level 2. The above step 1 describes the module of Hazard. Where in Level 0 the real time estimation of casualties will be performed in regional- 
level based on its population without estimating of building damages and economic losses. And Level 1 module estimates the losses of casualties related with damaged buildings, so the calculation of these buildings has been obtained from intensity based empirical vulnerability relationship. The same results have been achieved in module Level 2, and the differences are that the spectral acceleration-displacement-based vulnerability assessment methodology is used to compute the number of damaged buildings, and other difference that the estimation of casualties caused by damaged buildings is based on HAZUS99 (FEMA, 1999) and HAZUS-MH (FEMA, 2003) methodologies (ELER, 2010).

\subsection{HAZUS}

HAZUS (HAZard United States) is a free tool which is developed by the Federal Emergency Management Agency (FEMA) and released in 1997. It based on GIS (Geographical Information System) and analysis of natural hazard such as earthquakes, floods, hurricanes, and tsunamis to obtain potential losses, these are physical, economic, and social impacts of disasters. HAZUS used the capacity spectrum method to estimate claims over a variety of ground motion intensities. Relating to these demands and by using fragility curves for structural and non-structural losses, the computing of the potential losses will be done.

Like other methods of ELE, HAZUS needs data about building such as Structural system, occupation level, area of floor, height of a storey, construction year, cost of replacement, evaluation period, site location and other factors and details from HAZUS database (obtained from FEMA 310 worksheet), like lateral force resistant system, the connection detailing, floor diaphragms, non-structural components, others. In addition to the data of earthquake hazard should be given. The results that obtain from HAZUS are losses estimation and they are depending on the following predefined damage limit states: None, Slight, Moderate, Extensive and complete damage, these are illustrated in Figure 5 (Kircher, et al., 2006).

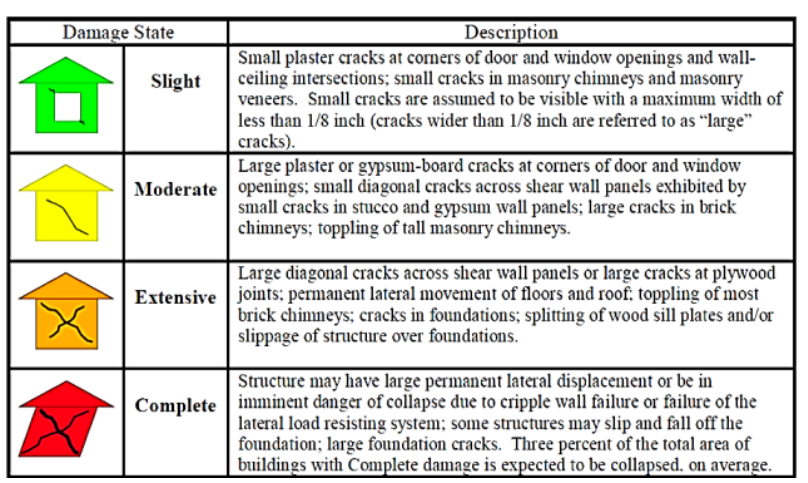

Fig. 5. Damage states in HAZUS (Charles A. et al.).

As described in HAZUS-MH official website, the HAZUS earthquake model estimates damage and loss of buildings, lifelines and essential facilities from scenario and probabilistic earthquakes, including [4]:
- Ground shaking and ground failure;

- Estimates of casualties;

- Displaced households and shelter requirements;

- Damage and loss of use of essential facilities;

- Estimated cost of repairing damaged buildings;

- Quantity of debris;

- Damage to buildings;

- Direct costs associated with loss of function (e.g., loss of business revenue).

It consists of just U.S. state or territory datasets; the international users have to contact with the developer for technical assistance regarding to other regions. Some other limitations of HAZUS are: 1) The outcomes present the average for a group of similar buildings, in reality also these buildings may have different damages and losses 2) According to various studies, the losses obtained from small magnitude less than 6 and in some region are overestimated (FEMA, 2003).

\subsection{SLAT}

SLAT (Seismic Loss Assessment Tool) is a web-based interface computer tool which is developed by University of Canterbury in New Zealand in 2009 for performing seismic loss assessment of structures that subjected to earthquake-induced hazards. It is compatible with Microsoft operating system and written in FORTRAN programing language. SLAT is based on the framework of performance-based seismic engineering which is developed by Pacific Earthquake Engineering Research Centre (PEER) that obtained a probabilistic seismic loss estimation (Bradley, et al., 2018). SLAT could be applied to compute ELE in buildings and bridges. It has inbuilt database; the user should select the data that fulfil the requirements of the structure. Each data set consists of the following items of data (Bradley, 2009): Title for the analysis, Principal analysis options, Correlation options, Integration methods, Output plotting parameters, Intensity measures, Engineering demand parameters, User defined fragility functions, Performance group, Global collapse, Parametric equations, Epistemic uncertainties, Repair downtime, External data files and Ranges for output data.

SLAT uses Web interface provides black box method, for this reason data processing systems and user need additional knowledge to understand and use the system. Also, current version of SLAT considers only the ground motion shaking at a single site. There is potential to extend it to handle spatially distributed problems such as transportation networks (Bradley, et al., 2018). SLAT is mainly focusing on earthquakes related to New Zealand because its development stage.

\subsection{FEMA P-58}

FEMA P-58 is a novel probabilistic performance prediction technique which is developed by Federal Emergency Management Agency (FEMA) and released in 2012. And it uses a Performance-Based Seismic Design (PBSD) concept by using of various 
performances measures that can easily be understood and interpreted by decision makers. The performance objective of this methodology is based on the level of damage by a building and the likely results of the damage including possible loss of occupancy, casualties, and reconstruction as well as repair costs.

The methodology is published in three volumes and volume one includes methodology, volume two describe the implementation guide, while the third volume consist of supporting products, these are electronic materials and background documentation. The main tool that used to implement this method is PACT (Performance Assessment Calculation Tool). It helps applicants to accumulate building performance models and carry out recurring calculations linked with the Monte Carlo analysis. It provides models for ten different types of buildings depending on its usage. These include commercial offices, healthcare, hospitality, residential buildings.

In order to identify and categorized fragility curve according to the component types, PACT uses NISTIR 6389 classification systems. This system is based on the UNIFORMAT II classification system. This system has six main categories and four sub levels.

In order to apply FEMA P-58 methodology for a specific building, many data should be collected to achieve an accurate result. These data include details about the building and their likelihood of damage when exposed to seismic activities. It's requires information regarding to site location, structural system, occupancy, number of floors, structural and non-structural components and their location and vulnerability, etc. The other important input data is defining the earthquake hazard. FEMA P-58 provide three types of assessment that can be categorized into intensity, scenario, and timebased assessments. This method is applicable for estimating the performance for both new and existing building.

After defining of the performance level and entering the input data of the building and ground motion, the analysis will be performing to obtain the building responses and develop the collapse fragility function. The user then will be evaluating a performance assessment, which is intended to determine if the selected performance level is met, or exceeded, at the chosen hazard level.

In any assessment, the consequences of building collapse include the causalities, the cost repair the building and downtime. These consequences are calculated by utilizing many large numbers to get the bests and predictable outcomes in such conditions of uncertainty.

As summary of the procedure of FEMA P-58, the Volume1 provides a detailed description of the methodology, the main steps for this methodology are:

- Assemble Building Performance Model;

- Define Earthquake Hazards;

- Analyse Building Response;

- Develop Collapse Fragility;

- Calculate Performance: Intensity Based and Scenario

Based Assessments or Time-Based Assessments.

Figure 5 illustrated the procedure of FEMA P-58.
The limitations by using performance assessment methodology are it take into account the losses within the building without consider the possibility of losses in power, water and sewage services, and without consider the damages and casualties outside the building when damage leads to debris that falls in the surrounding area. Also, it's not taken into account the probable significant impacts such us initiation of fire and release of dangerous materials.

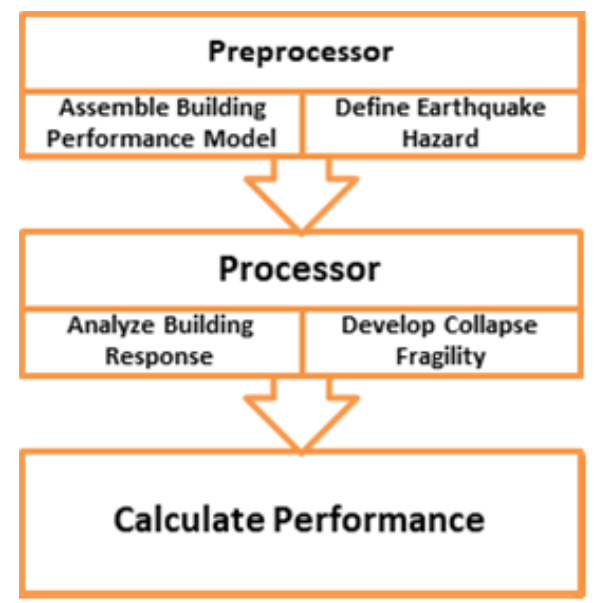

Fig. 6. Procedure of FEMA P-58.

\section{Estimation of earthquake losses by applying PACT}

\subsection{Site Location and Site Hazard}

- Occupancy : Office

- Location: Bucharest

- 1: $0.7 \mathrm{sec}\left(=0.075^{*}\left(\mathrm{H}^{\wedge} 0.9\right)\right), \mathrm{H}=12 \mathrm{~m}$

\begin{tabular}{|c|c|c|c|c|}
\hline $\begin{array}{c}\text { Intensity } \\
\text { Level }\end{array}$ & $\mathbf{S}_{\mathbf{a}}(\mathbf{T 1})$ & $\mathbf{M A F}$ & Mean $\mathbf{M}$ & Mean $\mathbf{R}$ \\
\hline $\mathrm{S}_{\mathrm{a} \_ \text {min }}$ & 0.04 & $1.13 \mathrm{E}-01$ & -- & -- \\
\hline Intensity 1 & 0.16 & $2.52 \mathrm{E}-02$ & 6.7 & 80 \\
\hline Intensity 2 & 0.39 & $4.71 \mathrm{E}-03$ & 7 & 40 \\
\hline Intensity 3 & 0.61 & $1.56 \mathrm{E}-03$ & 6.9 & 26 \\
\hline Intensity 4 & 0.84 & $6.56 \mathrm{E}-04$ & 6.9 & 18 \\
\hline Intensity 5 & 1.07 & $3.23 \mathrm{E}-04$ & 6.9 & 13 \\
\hline Intensity 6 & 1.3 & $1.71 \mathrm{E}-04$ & 6.8 & 10 \\
\hline Intensity 7 & 1.53 & $9.94 \mathrm{E}-05$ & 6.8 & 8 \\
\hline Intensity 8 & 1.76 & $5.74 \mathrm{E}-05$ & 6.8 & 7 \\
\hline Sa_max & 1.87 & $4.47 \mathrm{E}-05$ & -- & -- \\
\hline
\end{tabular}

MAF: mean annual frequency of exceedance (PACT)

M: Dominant contributing magnitude (M),

$\mathrm{R}$ : Site- source distance (R).

Ground motions were selected to match the Conditional Mean Spectrum (CMS) (Baker 2011) which is one of the two allowable options in the ATC-58 Methodology. 


\subsection{Building information}

Reinforced concrete (Moment Resisting Frame) for a building located in Bucharest.

Table 1. Building information.

\begin{tabular}{|l|c|c|}
\hline Description & \multicolumn{2}{|c|}{ Dimensions (m) } \\
\hline No. spans & 4 & 4 \\
\hline No. bays & 2 & 6 \\
\hline No. Story & 3 & 3 \\
\hline Ground level & 1 & 3 \\
\hline \multicolumn{2}{|c|}{192} \\
\hline Total floor area $\mathrm{m}^{2}$ & \multicolumn{2}{|c|}{768} \\
\hline Total building area $\mathrm{m}^{2}$ & \multicolumn{2}{|c|}{} \\
\hline
\end{tabular}

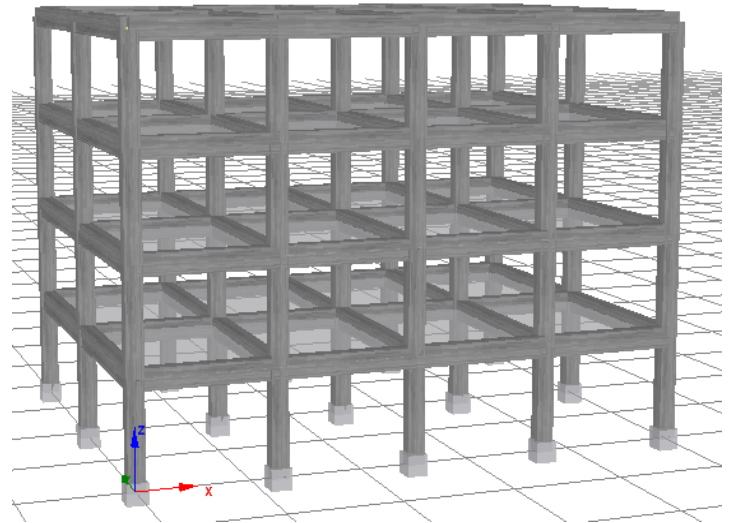

Fig. 7. Building 3D Model.

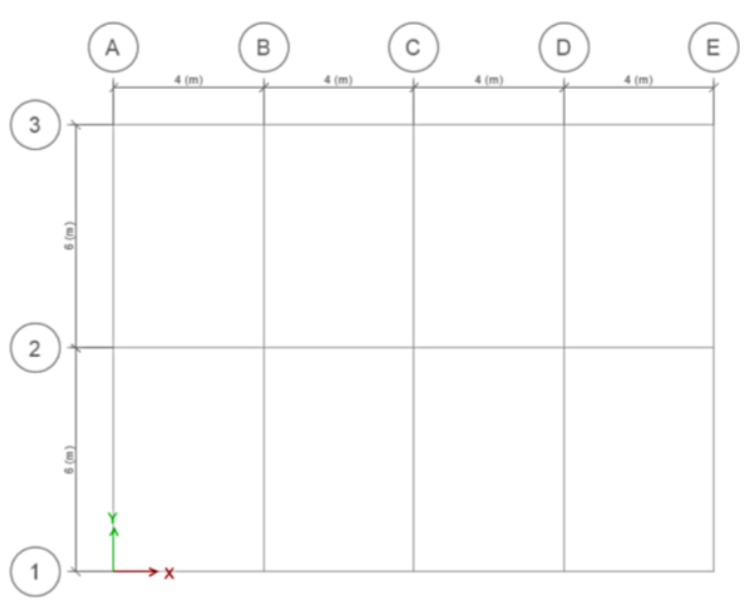

Fig. 8. Plan of the building.

\subsection{Costs details}

Table 2. Cost details.

\begin{tabular}{|l|l|}
\hline Cost Eur $/ \mathrm{m}^{2}$ & 600 \\
\hline Cost USD $/ \mathrm{m}^{2}$ & 678 \\
\hline Core and Shell replacement Euro/m2 & 400 \\
\hline
\end{tabular}

\begin{tabular}{|l|l|}
\hline Core and Shell replacement per USD/ m2 & 452 \\
\hline \multicolumn{2}{|l|}{} \\
\hline Total replacement cost Euro & 460800 \\
\hline Total replacement cost USD & $\mathbf{5 2 0 7 0 4}$ \\
\hline Core and Shell replacement Euro & 307200 \\
\hline Core and Shell replacement USD & $\mathbf{3 4 7 1 3 6}$ \\
\hline
\end{tabular}

\subsection{Population}

Table 3. Population.

\begin{tabular}{|l|l|}
\hline Peak number of occupants per 1000 sf & 4 \\
\hline Population Dispersion & 0.2 \\
\hline
\end{tabular}

In terms of earthquake the population ratio has a great effect, according to Philippe and Max, they found that if applying the same earthquake scenarios and the time of earthquake occurrence that happened in the past on the current population, the average number of fatalities will be 4 times higher than the fatalities due to increasing of the population. So, it should take in the consideration when estimate the losses of earthquake.

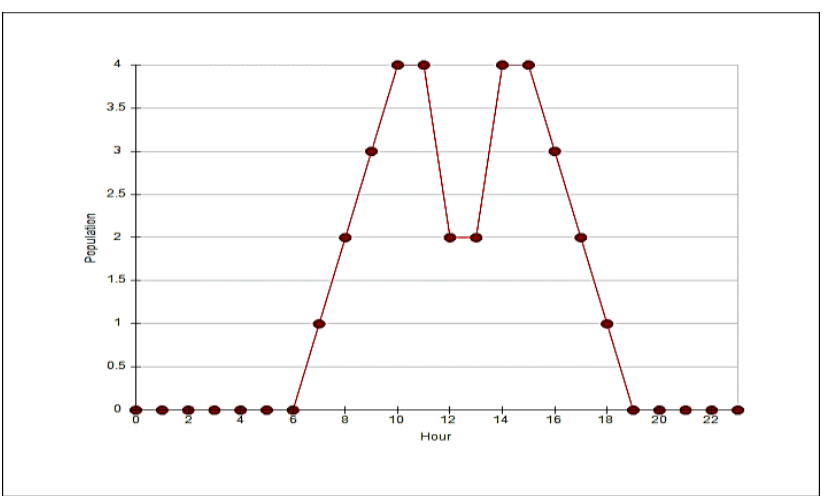

Fig. 9. Population Model.

According to distribution of population during the weekday hours and the weekend hours, it easy to identify the building purposes, and then helping in estimate the losses of earthquake. So, from figure 8 , the using of this building is commercial office as well described in (FEMA, 2012).

\subsection{Fragilities}

Fragility curves is a statistical tool representing the probability of exceeding a given damage state (or performance) as a function of an engineering demand parameter that represents the ground motion (preferably spectral displacement at a given frequency).

\section{Some results}

Earthquakes have demonstrated that they can not only destroy buildings and cause mass casualties, but also create enormous financial burdens to building owners as a result of business interruption losses. In 2010, a 
magnitude 8.8 earthquake struck Concepcion in Southern Chile demonstrating the crippling effects that non-structural damage can cause a densely populated urban area (Miranda et al., 2012). Buildings with only minor structural damage sustained significant nonstructural damage and this widespread damage precipitated building closures, which resulted in significant economic losses and major disruption to Chilean society. However, the results below estimating the repair costs and time for the direct earthquake losses as well as the fatalities and injuries.

\subsection{Repair costs}

In civil engineering, the repair cost is related to the repair time and the size of the building as well as the type of materials that used to construct this building and the purpose of the building.

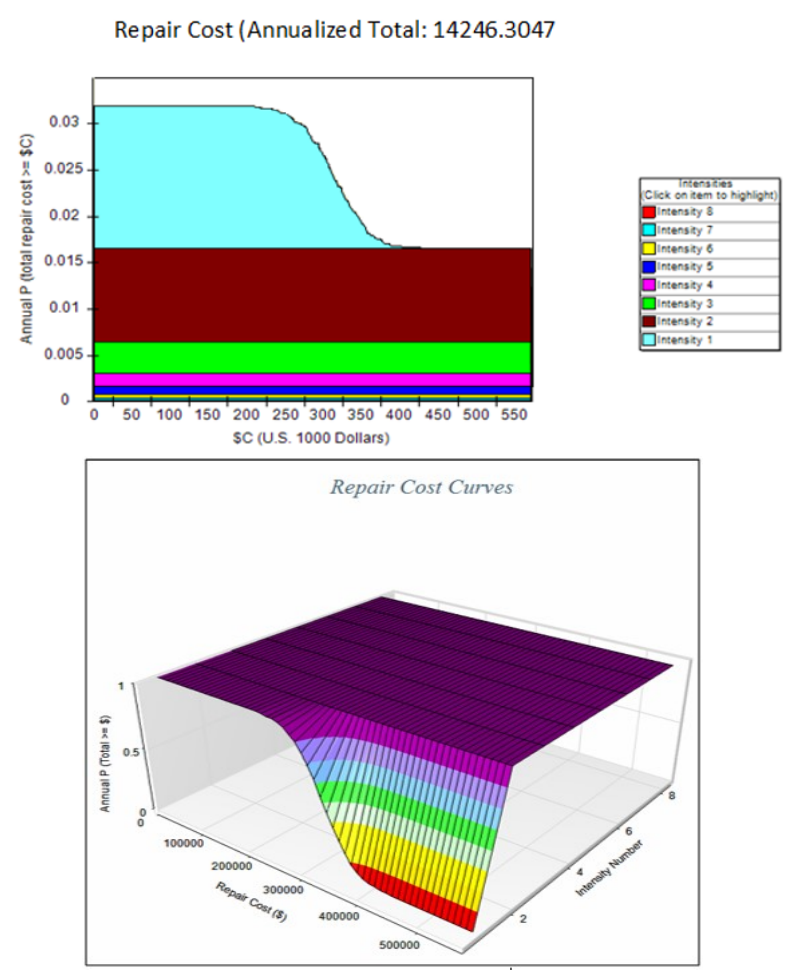

Fig. 10. Repair cost related to intensities.

\subsection{Repair time}

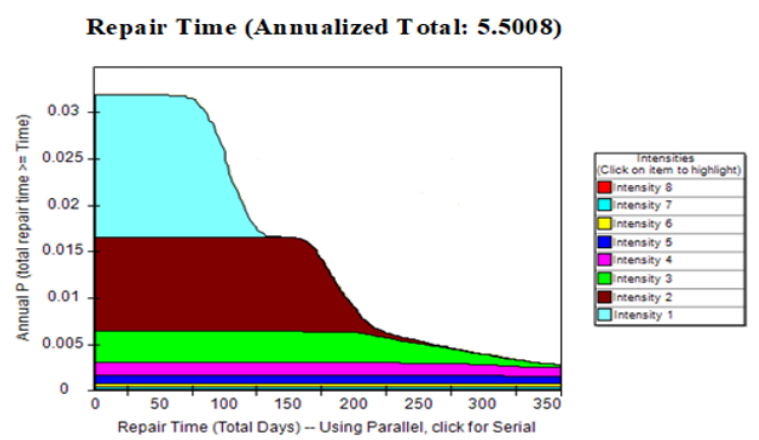

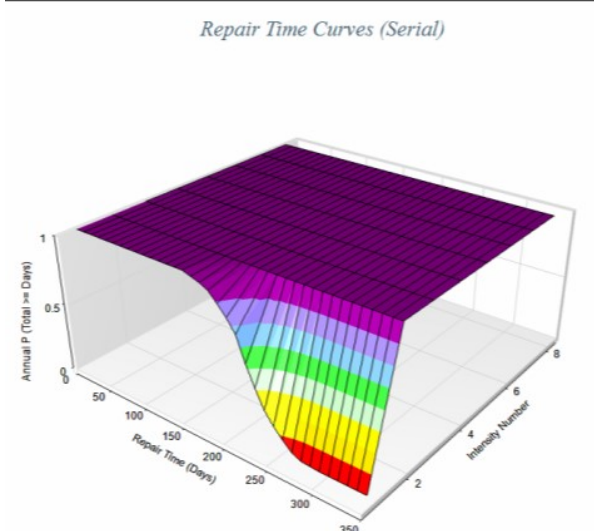

Fig. 11. Repair time related to intensities

\subsection{Fatalities and Injuries}

One of the most critical point in any earthquake disaster is the injuries number because any delay in estimation the numbers of injuries will lead to change their classification from injuries to fatalities. Recent advances are improving the speed and accuracy of loss estimates immediately after earthquakes (within less than an hour) so that injured people may be rescued more efficiently. After major and large earthquakes, rescue agencies and civil defense managers rapidly need quantitative estimates of the extent of the potential disaster, at a time when information from the affected area may not yet have reached the outside world. For the injured below the rubble every minute counts. To rapidly provide estimates of the extent of an earthquake disaster is much less of a problem in industrialized than in developing countries.

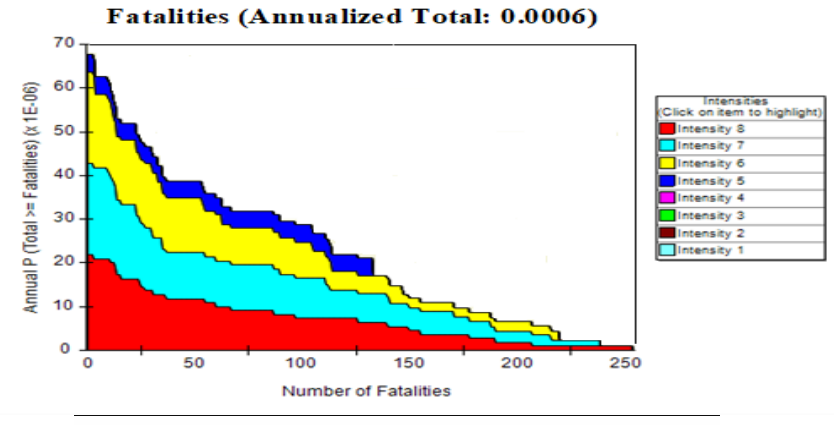

Fatality Curves

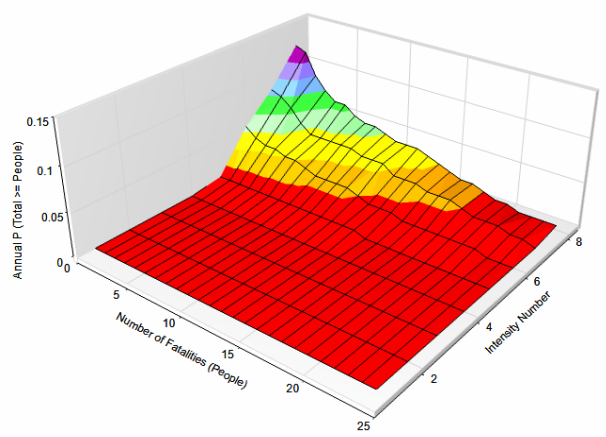

Fig. 12. Fatalities number related to intensities 


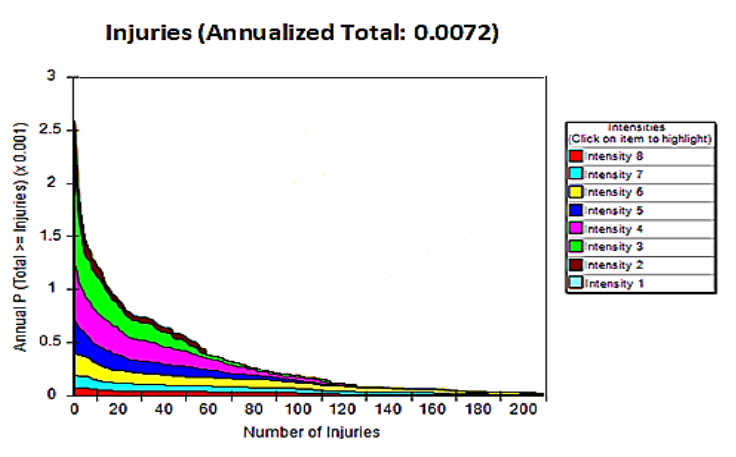

Injury Curves

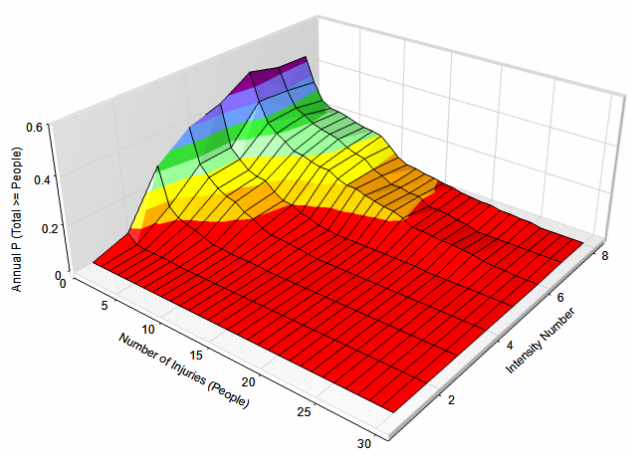

Fig. 13. Injuries related to Intensities.

Using the results of all eight intensities adjusted for their corresponding annual probabilities of exceedance, typical annualized loss metrics are shown in Figures 1013. The Figures 12 and 13 shows annualized values for: repair costs, repair time and fatalities respectively.

The various colours (shades) correspond to different intensity levels such that the annual contribution (probabilistically) can be visualized. Since the 4-story PEER benchmark building is a modern code-conforming design, it is logical that the annualized fatalities (although low in value) are coming from the highest intensity levels whereas the repair costs and repair time due to damage are controlled by the low (yet frequent) intensity events. However, the repair cost, the time of repair, injuries and the fatalities number are increasing with increasing the earthquake intensities as shown in the previous figures.

\section{Conclusion}

This report reviewed the state-of-the-art of earthquake loss estimation methodologies. Where six methods and tools earthquake loss estimation (ELE) were discussed in addition to explain what the easiest method (Fragility curve) as well as the latest way FEMA P-58. In general, there are a large range of earthquake loss estimation methods available with the unique target of mitigation of seismic losses.

In general, the authorities use the ELE methods that obtain the socio-economic losses on the building stock level of minimum geographical units like QLARM, SELENA, ELER, PAGER, etc. The property owners and investors focus more on the methods for estimation the losses in building level like HAZUS, SLAT, FEMA P58 , etc. The insurance companies and research could be interested in both categories of ELE methods. That is not just the unique factor for selection the suitable method, the other factors such as location, losses westimation in real time, framework, database, using of software and others are also important.

Thus, to estimate the earthquake losses for a specific building FEMA P-58 is recommended for using because of depending the method on Resilience-Based Design (generation 2 of performance-based design PBD) that means it including safety (casualties), repair time, repair cost and also support modelling and scrutiny of the design. FEMA P-58 has over 700 standard number of fragility and provides a clear and detailed user manuals and inbuilt functions can be identified through the provided, also user can update the consequence functions. Furthermore, the analysis includes the specific small differences of the building, rather than being based on building class.

However, this report tries to estimate the repair cost and time as well as the fatalities and injuries numbers depending on the earthquake facilities. And the repair cost and time increase with increase the earthquake intensities. While the numbers of fatalities and injuries are related to many other factors in addition to the intensities of earthquake such as the building purposes, construction materials and the construction year which also increase with increasing the earthquake intensities as clearly demonstrated in the Figures 12 and 13.

\section{References}

1. C. Corbane, U. Hancilar, D. Ehrlich, and T. De Groeve. Bulletin of earthquake engineering. PanEuropean seismic risk assessment: a proof of concept using the Earthquake Loss Estimation Routine (ELER). 15(3), pp.1057-1083 (2017).

2. H. Chaulagain, H. Rodrigues, V. Silva, E. Spacone and H. Varum. Bulletin of Earthquake Engineering. Earthquake loss estimation for the Kathmandu Valley. 14(1), pp.59-88 (2016).

3. J.E. Daniel, F. Wenzel and A.M. Schaefer. The Use of Historic Loss Data for Insurance and Total Loss Modeling. In Risk Modeling for Hazards and Disasters (pp. 107-137) (2018).

4. P. FEMA. 58-1 (2012) Seismic performance assessment of buildings (volume 1-Methodology). Federal Emergency Management Agency, Washington (2012).

5. C. Fugate. Senate Committee on Homeland Security and Governmental Affairs, Subcommittee on Disaster Recovery and Intergovernmental Affairs. Understanding the power of social media as a communication tool in the aftermath of disasters. (2011).

6. S.Molina, D.H. Lang and C.D. Lindholm. Computers \& Geosciences. SELENA-An opensource tool for seismic risk and loss assessment 
using a logic tree computation procedure. 36(3), pp.257-269 (2010).

7. R.Song, Y. Li and J.W. Van de Lindt. Structural Safety. Loss estimation of steel buildings to earthquake mainshock-aftershock sequences. 61, pp.1-11 (2016).

8. H.R. Ranjbar, H. Dehghani, A.R.A. Ardalan and M.R. Saradjian. Geomatics, Natural Hazards and Risk. A GIS-based approach for earthquake loss estimation based on the immediate extraction of damaged buildings. 8(2), pp.772-791 (2017).

9. L. Sousa, V. Silva, M. Marques, H. Crowley and R. Pinho. Including multiple IMTs in the development of fragility functions for earthquake loss estimation. In Vulnerability, Uncertainty, and Risk: Quantification, Mitigation, and Management (pp. 1716-1725) (2014).

10. L. Sousa, V. Silva, M. Marques and H. Crowley. Earthquake Engineering \& Structural Dynamics. On the treatment of uncertainties in the development of fragility functions for earthquake loss estimation of building portfolios. 45(12), pp.1955-1976 (2016).

11. N. Shome, N. Jayaram, H. Krawinkler and M. Rahnama. Earthquake Spectra. Loss estimation of tall buildings designed for the peer tall building initiative project. 31(3), pp.1309-1336 (2015).

12. G.A. Weatherill, V. Silva, H. Crowley and P. Bazzurro. Bulletin of Earthquake Engineering. Exploring the impact of spatial correlations and uncertainties for portfolio analysis in probabilistic seismic loss estimation. 13(4), pp.957-981 (2015).

13. J. Zschau, P. Gasparini \& G. Papadopoulos. SAFER Seismic Early Warning for Europe FINAL REPORT (2009).

14. Icesfoundation.org. (2013). ICES Foundation. [online] Available at: http://www.icesfoundation.org/Pages/CustomPage.a spx?ID=122 [Accessed 3 Jan. 2019].

15. R. Philippe, and W. Max. Civil Engineering Research Journal. Seismic Loss Assessment in Algeria Using the Tool QLARM. 2(2) (2017).

16. NORSAR. (2010). Earthquake Loss Estimation. [online] Available at: https://www.norsar.no/r$\mathrm{d} /$ safe-society/earthquake-hazard-risk/earthquakeloss-estimation/ [Accessed 3 Jan. 2019].

17. ELER. NEtwork of Research Infrastructures for European Seismology, " Earthquake Loss Estimation Routine ELER (C) v3.0, Technical Manual and Users Guide" (2010)

18. D. Cook, K. Fitzgerald, T. Chrupalo and C.B. Haselton. COMPARISON OF FEMA P-58 WITH OTHER BUILDING SEISMIC RISK ASSESSMENT METHODS (2017).

19. B. Bradley. Seismic Performance and Loss Assessment Tool (SLAT/OpenSLAT). (2018) [online] Sites.google.com. Available at: https://sites.google.com/site/brendonabradley/softwa re/seismic-performance-and-loss-assessment-toolslat [Accessed 14 Jan. 2019].

20. B.A. Bradley. User manual for SLAT: seismic loss assessment tool version 1.14 (2009).

21. J.E. Daniell. Natural Hazards and Earth System Sciences. Open source procedure for assessment of loss using global earthquake modelling software (OPAL). 11(7), pp.1885-1899 (2011).

22. L.E. Methodology. Technical manual. Washington, DC: Federal Emergency Management Agency (FEMA) (2003). 